\title{
BMJ Open Applying a whole systems lens to the general practice crisis: cross-sectional survey looking at usage of community pharmacy services in England by patients with long-term respiratory conditions
}

Ali Mawfek Khaled Hindi (D) , ${ }^{1,2}$ Ellen Ingrid Schafheutle (D) , ${ }^{1,2}$ Sally Jacobs (D) ${ }^{1,2}$

To cite: Hindi AMK, Schafheutle El, Jacobs S. Applying a whole systems lens to the general practice crisis: cross-sectional survey looking at usage of community pharmacy services in England by patients with long-term respiratory conditions. BMJ Open 2019;9:e032310. doi:10.1136/ bmjopen-2019-032310

- Prepublication history and additional material for this paper are available online. To view, please visit the journal (http:// dx.doi.org/10.1136/bmjopen2019-032310).

Received 12 June 2019 Revised 11 September 2019 Accepted 16 October 2019

D) Check for updates

(C) Author(s) (or their employer(s)) 2019. Re-use permitted under CC BY-NC. No commercial re-use. See rights and permissions. Published by BMJ.

${ }^{1}$ Centre for Pharmacy Workforce Studies, Division of Pharmacy and Optometry, The University of Manchester, Manchester, UK ${ }^{2}$ School of Health Sciences, Faculty of Biology, Medicine and Health, The University of Manchester, Manchester, UK

Correspondence to

Dr Ali Mawfek Khaled Hindi; ali.hindi@manchester.ac.uk

\section{ABSTRACT}

Objective UK policy initiatives aiming to extend community pharmacy services to moderate patient demands and to reduce general practitioners' (GPs) workload have had limited success. This study used marketing theory to identify factors that could influence patients to make better use of community pharmacies within the primary care pathway.

Design Cross-sectional postal survey design applying the '7Ps marketing mix' ('product', 'price', 'place', 'promotion', 'people', 'process' and 'physical evidence').

Setting Greater Manchester, England.

Participants Patients with asthma or chronic obstructive pulmonary disease registered at two GP practices.

Primary outcome Patient preference for community pharmacy services.

Results The response rate was 29\% (289/1003). Most respondents preferred to use GP practices for invasive/ diagnostic services (product) while preferring using community pharmacy for medicines supply and minor ailments (place). Stronger preference for using GP practices over community pharmacy was significantly associated with gender (male>female), age group ( $\geq 65$ years) and healthcare services previously accessed at the pharmacy. Respondents perceived they would be more likely to use community pharmacy services if pharmacists offered them enough time to discuss any concerns $(73.3 \%)$ (price), if community pharmacies had private/clean consultation rooms ( $70 \%-73 \%$ ) (physical evidence) and if pharmacy staff had strong interpersonal skills $(68 \%-70 \%)$ (people). Respondents were divided on likelihood of using community pharmacy services if pharmacists could access their whole medical record but wanted pharmacists to add information about their visit (59.6\%) (process). Respondents would be encouraged to use community pharmacy for healthcare services if they were offered services by pharmacy staff or recommended/ referred to services by their GP (44\%) (promotion). Conclusions Using the 7Ps marketing mix highlighted that community pharmacies having staff with strong interpersonal skills, good quality consultation rooms and integrated information systems could positively influence
Strengths and limitations of this study

- This study is the first to apply marketing theory to explore how to improve patient uptake of community pharmacy services with a view to better integrate community pharmacy services into the patient pathway and to reduce general practitioner (GP) workload pressures.

- This study was informed by, and adds to, previous findings from an earlier study examining awareness, uptake and integration of community pharmacy services within primary care.

- Most studies have explored patient preferences for specific community pharmacy services in isolation without accounting for their overall preference to receive healthcare from their GP practice. Instead, this study asked patients to state their preference between receiving services for long-term condition services from GP practices and community pharmacies, and the factors that influence these preferences.

- This survey was confined to one region and therefore may not be wholly representative of patients in England.

- The low survey response rate increased the potential of non-response bias.

patients to use community pharmacies for management of long-term conditions. There are opportunities for community pharmacies to alleviate GP workload, but a whole system approach will be necessary.

\section{INTRODUCTION}

Increasing patient demand has led to a substantial increase in both the volume and complexity of general practitioner (GP) workload. ${ }^{1}$ Furthermore, fewer GPs work full-time and many retire at an earlier age. ${ }^{2}$ In England, long-term conditions (LTCs) make up 50\% of all GP appointments and 
$70 \%$ of acute and primary care expenditures. ${ }^{3}$ The rise in patients with LTCs poses a challenge for GP practice to maintain efficient and high-quality services. ${ }^{4}$ The number of GPs who report working outside their regular hours has been steadily increasing, and patients are finding it more difficult to obtain GP appointments. ${ }^{5-7}$ In light of this crisis, policy initiatives have focused on developing new strategies to meet the needs of patients with LTCs and to reduce GP workload pressures. ${ }^{8-10}$

The potential role of community pharmacies as accessible primary care venues ${ }^{9}$ that could meet some of the needs of patients with LTCs has been recognised by policymakers in the UK. ${ }^{11}$ In 2005/2006, the NHS introduced community pharmacy contracts that reimburse community pharmacies for clinical, medicine-related and public health services, in addition to dispensing. ${ }^{12}$ As a result, LTCs such as respiratory illnesses, diabetes and cardiovascular diseases have become increasingly managed in community pharmacies. ${ }^{13}$ There is also reasonable evidence demonstrating the positive impact and various contributions that community pharmacy services can offer for patients with LTCs, such as enhancing medication adherence, improving the control of symptoms and reducing hospitality. ${ }^{14-16}$

However, patient awareness and use of these services have been low, and community pharmacy services are commonly not integrated with other primary care services. ${ }^{17} 18$ Moreover, patients have been sceptical towards the purpose of using community pharmacy for LTCs and generally prefer their GP practice instead. ${ }^{13} 1819$ In order to provide evidence-based community pharmacy services that integrate with primary care and thus achieve the potential of shifting demand away from GP practices and optimising patient care, it is important to understand the reasons patients with LTCs might use community pharmacy services over those offered by their GP practice. This study aimed to use marketing theory to identify factors that could influence better use of community pharmacy services within the primary care pathway. ${ }^{20}$

\section{METHODS}

\section{Participants}

Adult patients with asthma/chronic obstructive pulmonary disease (COPD) were chosen as they are among the most common users of primary care consultations, ${ }^{21}$ and a range of relevant community pharmacy services already exist (eg, inhaler techniques, respiratory Medicines Use Reviews, smoking cessation and influenza vaccinations). ${ }^{22}$ Participants were eligible if aged at least 18 years and able to provide consent and complete the questionnaire.

The first author contacted eight GPs in Greater Manchester identified by known contacts, via email/telephone, asking them to participate in the study. Of these eight GPs, three declined, three did not respond to the invitation, and two GPs agreed to recruit participants for the study. Practice managers identified 1003 eligible patients through patient records. Assuming a response rate of $25 \%(\mathrm{n}=250)$, this sample size had $80 \%$ power to detect a correlation of 0.18 between any two derived continuous variables, based on a $5 \%$ level of statistical significance. $^{23}$

\section{Study procedure}

Practice managers were provided with recruitment packs (containing an invitation letter, a participant information sheet, a questionnaire and a reply paid envelope addressed to research team), which they posted between January and February 2019. Unique ID numbers allowed identification of non-respondents; one postal reminder was sent after 3 weeks.

\section{Questionnaire development}

The 7Ps marketing mix model (product, price, place, promotion, people, process and physical evidence) ${ }^{24}$ was used to frame this study, informed by a previous qualitative study ${ }^{20}$ and existing literature. ${ }^{1718}$ The 7Ps provide seven components hat are based on understanding what consumers want/ need from a service while accounting for the influence of service design, service delivery and external communications on consumers' perceptions of services. Previous studies have evaluated the impact of the 7Ps marketing mix elements on patients' willingness to use hospitals ${ }^{25}$ and online pharmacies. ${ }^{26}$ In addition, the 7Ps marketing mix has been used to identify key factors that influence patient preferences for using community pharmacy services. $^{2027}$

The questionnaire involved closed questions and Likert-type agreement statements on preferences for using services at the community pharmacy or GP surgery, and features influencing these preferences (online supplementary file 1). The questionnaire was piloted using cognitive interviews with a convenience sample of 12 people with LTCs (six with a respiratory condition) and 4 who used community pharmacies for collecting/ purchasing medications. ${ }^{28}$ After interviewing participants, the author collated responses from all the cognitive interviews and discussed them with the coauthors. Following the discussion, amendments were made to the wording of some items and one of the response scales (online supplementary file 2).

\section{Analyses}

Data on respondents' characteristics: preferences for using services at the community pharmacy or GP surgery, features influencing likelihood of using community pharmacy services and views on promotional strategies are reported descriptively. Responses to the frequency of community pharmacy use (less than/more than once per month), variety of pharmacies used (same/different pharmacy), age group (less than 65 years/more than 65 years of age) and type of services used by respondents (only medication supply/other services) were dichotomised.

Two sets of multivariable regression analysis were conducted to investigate respondent characteristics that influence their preferences and likelihood of using 
Table 1 Respondent characteristics ( $N=289)$

\begin{tabular}{ll}
\hline Characteristics & $\mathbf{n}(\%)^{*}$ \\
\hline Gender & \\
Male & $105(37.1)$ \\
Female & $178(62.9)$
\end{tabular}

Respiratory condition

\begin{tabular}{lc}
\hline Asthma & $158(57.7)$ \\
\hline COPD & $95(34.7)$ \\
\hline Both asthma and COPD & $17(6.2)$ \\
\hline Other breathing condition & $4(1.5)$ \\
\hline Age group (years) & $7(2.4)$ \\
\hline 18-24 & $14(4.9)$ \\
\hline 25-34 & $19(6.6)$ \\
\hline 35-44 & $36(12.6)$ \\
\hline $45-54$ & $61(21.3)$ \\
\hline 55-64 & $83(29.0)$ \\
\hline $65-74$ & $66(23.1)$ \\
\hline 75+ & \\
\hline Ethnicity & $258(90.2)$ \\
\hline White & $12(4.2)$ \\
\hline Asian & $6(2.1)$ \\
\hline Black & $6(2.1)$ \\
\hline Mixed/multiple ethnic groups & $4(1.4)$ \\
\hline Other & $25(8.7)$ \\
\hline Frequency of pharmacy use & $175(61.0)$ \\
\hline Less than once a month & $46(16.0)$ \\
\hline Once a month & \\
\hline Less than once a year & \\
\hline collects medications) & \\
\hline
\end{tabular}

Range of pharmacies used

Visits the same pharmacy all of the 186 (66) time

Visits a variety of different $\quad 54$ (19.1)

pharmacies but visit one most often

Visits a variety of different pharmacies and none more frequently than any other

Not applicable 23 (8.2)

${ }^{*}$ Respondent characteristics had missing/incomplete data. Percentages are based on the number of item responses. COPD, chronic obstructive pulmonary disease.

community pharmacy services for LTCs. A list of covariates was determined to address potential predictors, which included respiratory condition, gender, age group, service usage at pharmacy and frequency of pharmacy usage. The first regression model (linear) explored whether these respondents' characteristics were associated with 'service preference for community pharmacy over GP services' (a score derived from summing the Likert responses to items assessing preferences for using services at community pharmacy compared with GP practice, with higher scores indicating a greater preference for community pharmacy; three items were removed as they were applicable to less than $40 \%$ of the sample $(\alpha=0.839))$. The second (logistic) explored whether respondent characteristics were associated with 'likelihood of using community pharmacy services' (binary response to the statement 'I would be more likely to use the pharmacy than I currently do if all of the features ticked as "more/much more likely" were all in place').

For purposeful selection of covariates in the regression models, ${ }^{29}$ univariable analysis examined potential respondent characteristics associated with service preferences (independent sample t-tests) and likelihood of using community pharmacy services (Pearson's $\chi^{2}$ test). A conservative $p$ value of 0.2 was used to indicate a significant association. Independent variables that met this criterion were included in a multivariable regression model to examine if their association remained when controlling for other factors. Variables were then eliminated by stepwise removal, only being retained in the final model if significance at $\mathrm{p}<0.05$ was achieved. ${ }^{29}$

Quantitative analysis was conducted using SPSS V.22. Free-text responses were analysed based on commonly reoccurring themes. All comments were examined, categorised and themed in relation to the research question. Themes were juxtaposed with quantitative data to provide a better understanding and richer interpretation of the findings.

\section{Patient and public involvement}

This study is part of a larger $\mathrm{PhD}$ project. To ensure the project was grounded in patient priorities, members of the public were consulted about study design through the Patient and Public Advisory Board (PPAB) of The University of Manchester Division of Pharmacy and Optometry. Eight members of the public who took part in the PPAB were living with one or more LTCs and had experience using primary care services. Members were provided a lay summary of the $\mathrm{PhD}$ project and were consulted on the importance of the research topic. In addition, РPAB members were consulted on the participant information sheet and recruitment strategies for the focus group study, which informed this survey study.

\section{RESULTS}

Of 1003 mailed questionnaires, 289 were returned (29\% response rate). Most respondents were female (63\%), visited the pharmacy once a month $(61 \%)$ and used the same pharmacy most/all of the time (85\%). Most respondents had asthma (58\%), 35\% had COPD, and 6.2\% had both asthma and COPD or other breathing problems 


\begin{tabular}{|c|c|}
\hline Type of community pharmacy service used & $n(\%)^{*}$ \\
\hline Receiving medication that has been prescribed & $271(93.8)$ \\
\hline Buying medicines & $122(42.2)$ \\
\hline Advice on minor conditions & $97(33.6)$ \\
\hline Medication review consultation & $61(21.1)$ \\
\hline Influenza vaccination & $56(19.4)$ \\
\hline Assistance with medication use & $46(15.9)$ \\
\hline Inhaler technique & $28(9.7)$ \\
\hline $\begin{array}{l}\text { Help when breathing condition gets worse (eg, } \\
\text { breathlessness or coughing) }\end{array}$ & $12(4.2)$ \\
\hline Blood pressure checks & $11(3.8)$ \\
\hline $\begin{array}{l}\text { Regular check-ups for respiratory condition (eg, } \\
\text { spirometry tests) }\end{array}$ & $11(3.8)$ \\
\hline $\begin{array}{l}\text { Finger-prick blood tests (eg, for checking } \\
\text { cholesterol) }\end{array}$ & $7(2.4)$ \\
\hline Advice on vaccinations for travelling abroad & $6(2.1)$ \\
\hline Weight management & $2(0.7)$ \\
\hline Smoking cessation & $1(0.3)$ \\
\hline None of these services & $7(2.4)$ \\
\hline Other service & $4(1.4)$ \\
\hline
\end{tabular}

*Total for the type of community pharmacy services accessed by respondents exceeds $100 \%$ as respondents were asked to indicate all services that they used.

$(1.5 \%)$. The majority of respondents was white $(90.2 \%)$, and most $(73.4 \%)$ were 55 years and older. Respondent characteristics are shown in table 1 .

Table 2 lists community pharmacy services used by the respondents. The most commonly used services were traditional medicine supply, purchasing medicines and advice on minor ailments.

\section{Preferences for using different services at the community} pharmacy compared with GP practice ('product' and 'place')

Table 3 shows preferences for using different services at the community pharmacy compared with GP practice. Most respondents preferred using GP practice for more invasive/diagnostic services $(53 \%-89 \%)$. Community pharmacy was preferred for purchasing/receiving medicines and minor ailments $(45.5 \%-71.6 \%)$. Just under half of respondents either preferred GP practices or had no preference for receiving advice/assistance with medication usage and public health services.

The mean score $( \pm \mathrm{SD})$ for respondents' overall preference for using services at community pharmacy over GP practice was $28.45 \pm 8.374$ (range: 11 (prefer GP practice) -55 (prefer community pharmacy)). In the final linear regression model, age group (less than 65 years), gender (female) and already using healthcare services other than medication supply were significantly associated with a higher preference for receiving services at community pharmacy $(\mathrm{p}<0.05)$ (table 4$)$.
Pharmacy features influencing respondents' likelihood of using community pharmacy services ('price', 'physical evidence', 'people' and 'process')

Features influencing respondents' likelihood of using community pharmacy services are provided in table 5 . The feature that respondents perceived would make them most likely to use community pharmacy services was if the pharmacist offered them enough time to discuss any concerns $(73.3 \%$, price). Price-defined as added value from obtaining services from community pharmacies-was also important in patients being offered a follow-up appointment with the pharmacist (63.0\%). Physical evidence was important in terms of community pharmacies having clean $(72.9 \%)$ and private $(69.6 \%)$ consultation rooms with enough space $(58.5 \%)$.

In relation to people, the most important feature encouraging patients to use community pharmacies was if the pharmacist $(69.9 \%)$ and other pharmacy staff $(67.6 \%)$ were friendly and approachable. Respondents were divided on likelihood (more likely/no difference/ less likely) of using community pharmacy services if pharmacists could access patients' whole medical record, but $55.7 \%$ were less likely to use community pharmacies if other pharmacy staff had access. In terms of process, $60 \%$ of respondents perceived they would be more likely to use community pharmacy services if the pharmacist could add information to their medical record.

Almost half of the respondents indicated they would be more likely to use the pharmacy than they currently do if all of the features they wanted were in place $(47.7 \%)$. The final logistic regression model demonstrated that respondents who used community pharmacy for healthcare services other than purchasing/collecting medications were significantly more likely to use community pharmacy if the features they wanted were in place (table 4).

Sixty-seven respondents provided free-text comments, which offered insights into their reasons for not using/ preferring community pharmacy services for LTCs. Respondents mentioned community pharmacies having limited size, long waiting times, pharmacy staff's limited interpersonal skills and pharmacists' busyness with dispensing duties. Some of the respondents mentioned they would continue to use GP practices instead of community pharmacies as they had a strong relationship with GP practice staff, which was deemed absent with community pharmacy staff. When respondents commented on factors that would influence them to use community pharmacy services for their LTCs, they wanted to have earlier appointments at community pharmacies than their GP practices and to spend more time discussing any issues about their medications and condition.

\section{'Promotion' of community pharmacy services}

Respondents' views on promotional methods that could encourage their use of community pharmacy services are provided in figure 1. Being offered services by pharmacy staff when visiting the community pharmacy $(44.3 \%)$ or 
Table 3 Respondents' preferences for using services at community pharmacy compared with GP practice*

\begin{tabular}{|c|c|c|c|}
\hline Service (7Ps: 'product' and 'place') & $\begin{array}{l}\text { Strongly/slightly } \\
\text { prefer GP practice }\end{array}$ & $\begin{array}{l}\text { Strongly/slightly prefer } \\
\text { community pharmacy }\end{array}$ & $\begin{array}{l}\text { No } \\
\text { preference }\end{array}$ \\
\hline \multicolumn{4}{|l|}{ Prefer GP practice } \\
\hline $\begin{array}{l}\text { Help when symptoms for breathing condition get worse (eg, } \\
\text { breathlessness or coughing) }\end{array}$ & $236(89.1)$ & $7(2.6)$ & $22(8.3)$ \\
\hline $\begin{array}{l}\text { Regular check-ups to see how well breathing condition is } \\
\text { progressing (eg, spirometry tests) }\end{array}$ & $215(81.7)$ & $10(3.8)$ & $38(14.4)$ \\
\hline Consultation to review all the medications used & $163(65.2)$ & $37(14.8)$ & $50(20.0)$ \\
\hline Influenza vaccination & $145(61.2)$ & $27(11.4)$ & $65(27.4)$ \\
\hline Blood pressure checks & $150(60.2)$ & $22(8.8)$ & $77(30.9)$ \\
\hline Finger-prick blood tests (eg, for checking cholesterol) & $112(53.1)$ & $21(10.0)$ & $78(37.0)$ \\
\hline \multicolumn{4}{|l|}{ No preference } \\
\hline Advice on vaccinations for travelling abroad & $75(46.6)$ & $18(11.2)$ & $68(42.2)$ \\
\hline Help with inhaler technique & $97(43.7)$ & $40(18.0)$ & $85(38.3)$ \\
\hline Help with losing weight & $36(39.1)$ & $15(16.3)$ & $41(44.6)$ \\
\hline Assistance with how to take medications & $88(37.0)$ & $61(25.6)$ & $89(37.4)$ \\
\hline Help with stopping smoking & $19(34.5)$ & $13(23.6)$ & $23(41.8)$ \\
\hline \multicolumn{4}{|l|}{ Prefer community pharmacy } \\
\hline Buying medicines & $15(6.8)$ & $159(71.6)$ & $48(21.6)$ \\
\hline Getting advice on minor conditions (eg, cough or cold) & $40(16.8)$ & $134(56.3)$ & $64(26.9)$ \\
\hline Obtaining medication that has been prescribed & $83(30.2)$ & $125(45.5)$ & $67(24.4)$ \\
\hline
\end{tabular}

* One of the response options was 'not applicable' as some of the services may not apply to all respondents. Services that were not applicable to respondents were counted as missing data. Percentages are based on the actual number of individual responses to services. GP, general practitioner; 7Ps, product, price, place, promotion, people, process and physical evidence.

Table 4 Multivariable regression analysis of respondent characteristics associated with preference for GP practice/community pharmacy (linear regression) and likelihood of using community pharmacy (logistic regression)

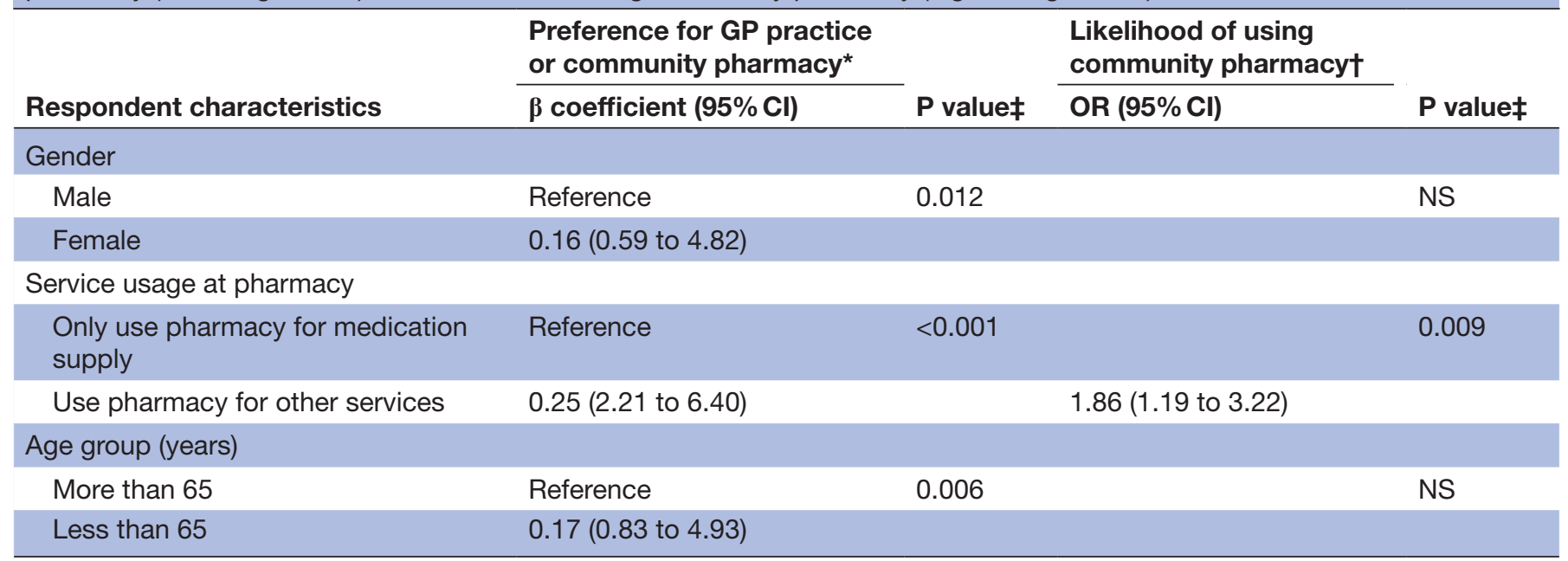

`Mean score for respondents' overall preference for using services at community pharmacy over GP practice (GP practice $=11$, community pharmacy $=55$ ).

†Binary response (yes/no) to the statement 'I would be more likely to use the pharmacy than I currently do if all of the features ticked as "more/much more likely" were all in place'.

$\ddagger$ Statistical significance $(p<0.05)$.

GP, general practitioner; NS, non-significant. 


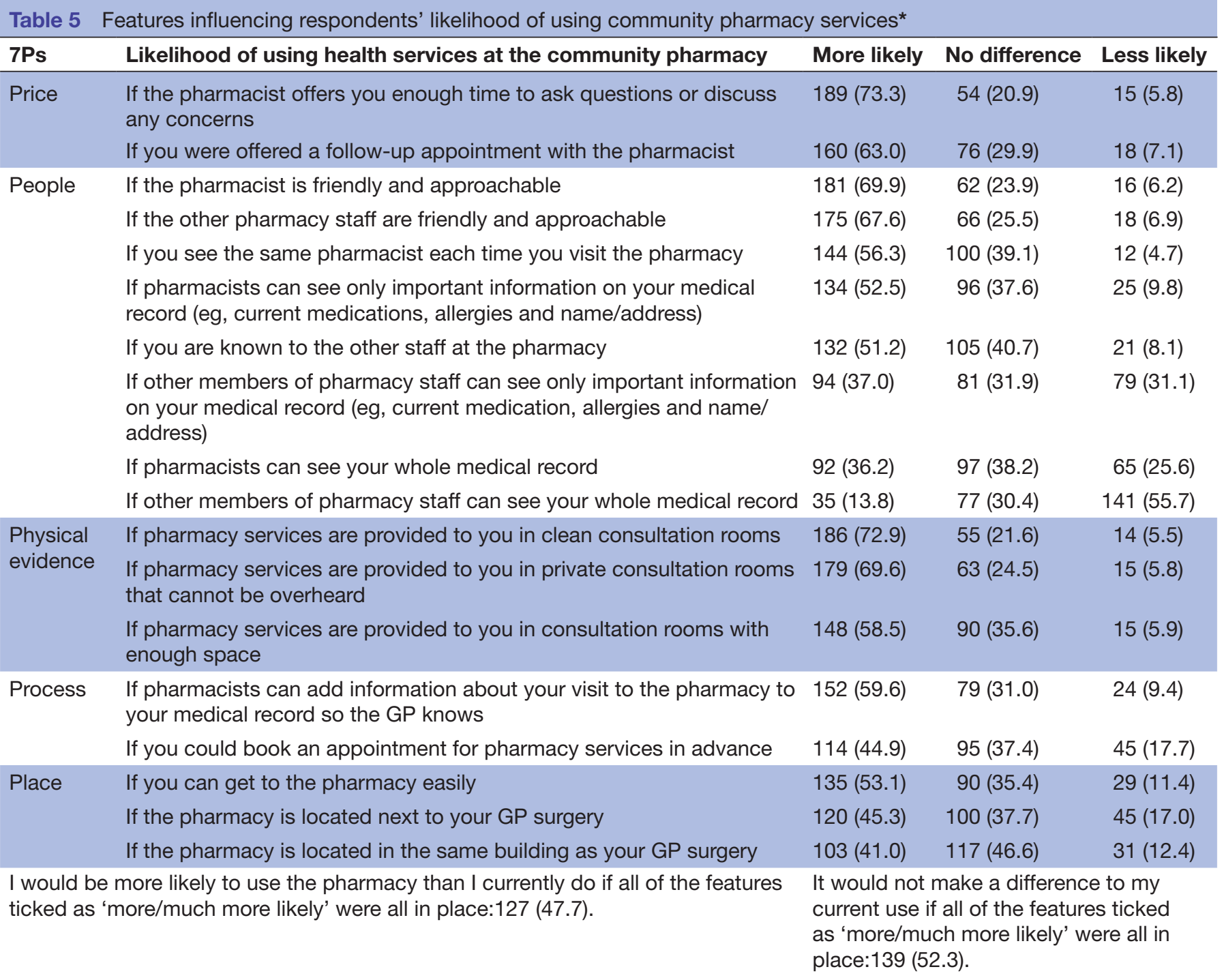

${ }^{*}$ Respondents had missing/incomplete data. Percentages are based on the number of item responses. GP, general practitioner; 7Ps, product, price, place, promotion, people, process and physical evidence.

their GP recommending/referring to services (43.6\%) were the most influential promotional methods.

\section{DISCUSSION}

\section{Principal findings}

This study was undertaken within the policy context of the burden of LTCs, GP shortages and workloads, and the potential for community pharmacies to contribute to the care of patients with LTCs. Considering the accessibility yet low patient awareness of services available in community pharmacy, this study used marketing theory to identify factors that influenced patients' healthseeking behaviour. Overall, patients were receptive to using community pharmacies for medicine management and minor ailments but were more reluctant to use them for invasive/diagnostic services and medication consultations. This survey of 289 patients with long-term respiratory conditions identified service characteristics that could encourage patients to use community pharmacy instead of GP practices, such as pharmacy staffs' interpersonal skills, community pharmacies having private/clean consultation rooms and integrated information systems with GP practices. Patients considered GP referral or recommendation to use pharmacies as the most effective forms of service promotion.

\section{Strength and weaknesses of this study}

The novel approach of using the 7Ps marketing mix model offers valuable insights into patients' preferences for LTC services at GP practices versus community pharmacy, and factors that influence these preferences. This study is limited because it involves only a convenience sample of patients from two GP practices in one geographical region. The low response rate of $29 \%$ increased the risk of non-response bias; however, this response rate is similar to GP patient surveys, ${ }^{30}$ and the sample size was statistically powered. 
Being offered health services by the pharmacy staff when visiting the pharmacy to pick up your...

Being recommended/referred to health services by a GP

Experiencing health services delivered to you in person

Seeing advertisements about health services on a poster/leaflet in a GP surgery

Seeing advertisements about health services on a poster/leaflet in a pharmacy

Receiving a text/email from the pharmacy about health services on offer

Seeing health services advertised on national media (e.g. television, radio, newspapers etc.)

Being recommended health services by friends/family members

Seeing health services advertised on social media (e.g. Facebook, Twitter)

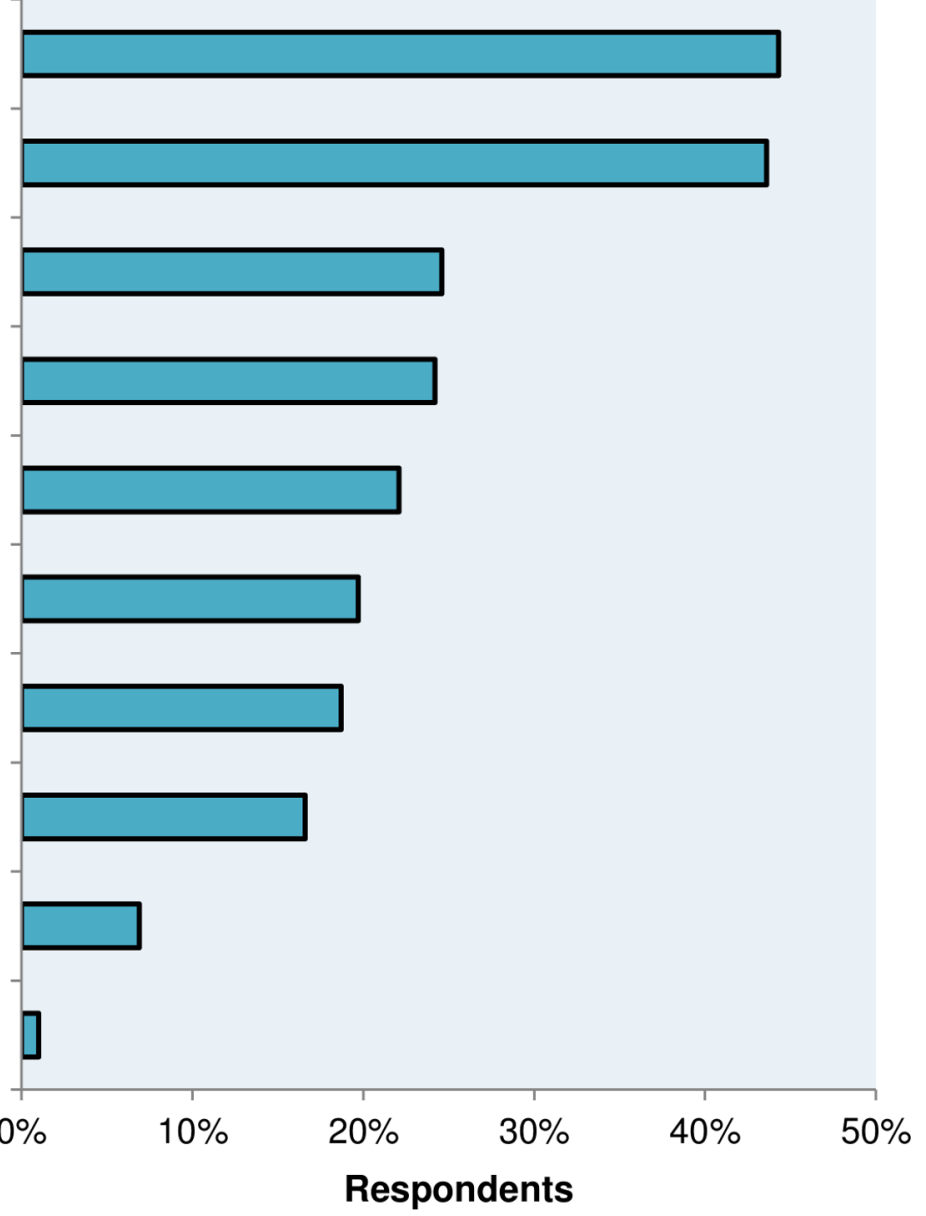

Respondents

Figure 1 Promotional methods that could encourage respondents to use community pharmacy services (7Ps: 'promotion'). GP, general practitioner.

\section{Comparison with existing literature}

Findings in this study confirm that patients' preference for using GP-led LTC services remain unchanged. ${ }^{18} 19$ However, the application of marketing theory has helped to identify key factors that could shift patients into community pharmacy and reduce GPs workload. Our data corroborate that GP endorsement is fundamental to patients' willingness to use community pharmacy services. ${ }^{20} 31$ Moreover, regression analysis strengthens previous findings, which suggest that patients who have experienced non-traditional pharmacy services are more receptive to using them despite initial reluctance. ${ }^{32-34}$ However, unlike previous studies, ${ }^{35}{ }^{36}$ participants in our study did not perceive recommendation by family/ friends to have a strong influence on their use of community pharmacy services.

Previous studies suggest that lack of privacy in community pharmacy settings negatively impacts patient/public perceptions. ${ }^{37-39}$ Our study builds on these findings by demonstrating the relative importance of consultation room features (size and privacy) on patients' likelihood of using LTC services at community pharmacy. Taken together with previous studies, it is evident that challenges regarding community pharmacy layouts and privacy requirements remain unresolved despite the increase in range and complexity of community pharmacy services.

To the authors' knowledge, this is the first UK study to quantitatively assess patients' views on the importance of pharmacists having read-write access to their medical records. ${ }^{20}{ }^{40}$ Some ambivalence was shown by patients as they were uncertain about pharmacists accessing their whole medical records but wanted them to add information. These findings could indicate a lack of public knowledge and the need for further public education on access to medical records. ${ }^{41}$ Internationally, studies in Australia and the USA have reported that patients prefer pharmacists accessing their full medical record with links to their GP practice. ${ }^{42} 43$

\section{Implications for policymakers}

Tackling the GP crisis requires a 'whole systems approach' rather than silo working to avoid misaligned incentives, duplicated work and shifting existing problems in general practice into another overstretched sector such as community pharmacy. Patients are still reluctant to consult pharmacists for issues relating to their LTCs or advanced services (eg, influenza vaccination). Interpersonal skills such as community pharmacists being approachable and 
offering patients enough time to discuss their concerns could encourage patients with LTCs to use community pharmacies for healthcare. However, community pharmacists have limited opportunity for face-to-face interactions with patients due to high dispensing workloads, limited staff and restrictive reimbursement models. ${ }^{134}{ }^{44}$ Policymakers should therefore reassess the current funding model for community pharmacy in the context of the need to transfer some routine/monitoring services out of general practice.

Medication review consultations at community pharmacy are generally provided ad hoc with inadequate privacy, therefore making them less desirable/ beneficial to patients who already receive GP practice reviews. ${ }^{38} 395$ With joined-up and coordinated healthcare services underpinning the NHS long-term plan, ${ }^{46}$ it is essential to have integrated information systems between community pharmacies and GP practices to improve the quality and safety of patient care by enhancing communication and reducing duplication.

This study also suggests that publicising community pharmacy services has limited influence on patients if they are not endorsed by GPs and pharmacists are not proactively offering them. Policymakers should be aware it is unlikely pharmacists will prioritise healthcare services over dispensing or that GPs will refer patients to community pharmacies under current reimbursement models. ${ }^{47}$ Thus, incentivising joint working between community pharmacists and GPs should be a key priority for policymakers seeking to lessen the burden on GP practices by enhancing patient demand and uptake of community pharmacy services. ${ }^{47} 48$

\section{Unanswered questions and future research}

This study conceptualised how community pharmacy services could be better used and integrated within the primary care pathway for patients with LTCs. After first confirming findings through a large national study, it would be necessary to test the feasibility of implementing new community pharmacy models of care, which offer medicine-related and/or public health services that integrate with GP practice through agreed referral pathways, feedback and follow-up processes.

Twitter Ali Mawfek Khaled Hindi @Ali_Hindi91, Ellen Ingrid Schafheutle @ EllenSchaf and Sally Jacobs @sallyjacobs23

Acknowledgements The authors thank the patients who took part in the study and the general practice managers who helped with recruitment. The authors also thank Dr Kelly Howells for her advice on recruitment, Dr Mark Hann for his advice on statistical analysis, and Dr Ireny Iskandar and Dr Alison Wright for their help with some inquiries related to statistical analysis.

Contributors AH, EIS, SJ designed the study. AH performed the analysis with input from EIS and SJ. AH drafted the manuscript, which EIS and SJ commented on and edited. The final manuscript was read and approved by all authors. AH is the guarantor.

Funding The authors have not declared a specific grant for this research from any funding agency in the public, commercial or not-for-profit sectors.

Competing interests None declared.

Patient consent for publication Not required.
Ethics approval This study received NHS Research Ethics Committee approval and NHS Health Research Authority approval (ref: 18/EM/0372).

Provenance and peer review Not commissioned; externally peer reviewed.

Data availability statement Data are available upon reasonable request.

Open access This is an open access article distributed in accordance with the Creative Commons Attribution Non Commercial (CC BY-NC 4.0) license, which permits others to distribute, remix, adapt, build upon this work non-commercially, and license their derivative works on different terms, provided the original work is properly cited, appropriate credit is given, any changes made indicated, and the use is non-commercial. See: http://creativecommons.org/licenses/by-nc/4.0/.

\section{ORCID iDs}

Ali Mawfek Khaled Hindi http://orcid.org/0000-0002-1076-435X

Ellen Ingrid Schafheutle https://orcid.org/0000-0001-7072-0888

Sally Jacobs http://orcid.org/0000-0002-6199-5748

\section{REFERENCES}

1 NHS England. General practice forward view, 2016. Available: https://www.england.nhs.uk/wp-content/uploads/2016/04/gpfv.pdf

2 Baird B, Charles A, Honeyman M, et al. Understanding pressures in general practice. The King's fund, 2016. Available: https://www. kingsfund.org.uk/sites/default/files/field/field_publication_file/ Understanding-GP-pressures-Kings-Fund-May-2016.pdf

3 Department of Health. Long term conditions compendium of information, 2012. Available: https://www.gov.uk/government/ uploads/system/uploads/attachment_data/file/216528/dh_134486. pdf

4 Primary Care Workforce Commission. The future of primary care: creating teams for tomorrow, 2015. Available: https://www.hee.nhs. uk/sites/default/files/documents/The\%20Future\%20of\%20Primary\% 20Care\%20report.pdf

5 Robertson R. Public satisfaction with the NHS and social care in 2017: results and trends from the British social attitudes survey. The King's fund, 2017. Available: https://www.kingsfund.org.uk/sites/ default/files/media/BSA_final2_Kings_Fund_Mar_2017.pdf

6 BMA. British Medical association: survey of GPs in England, 2016. Available: https://www.bma.org.uk/collective-voice/influence/keynegotiations/training-and-workforce/urgent-prescription-for-generalpractice/key-issues-survey

7 BMA. Bma quarterly survey: current views from across the medical profession, 2018. Available: https://www.bma.org.uk/collectivevoice/policy-and-research/education-training-and-workforce/ quarterly-survey/quarterly-survey-results/quarterly-survey-q2-2018

8 NHS. Five year forward view, 2014. Available: https://www.england. nhs.uk/wp-content/uploads/2014/10/5yfv-web.pdf

9 NHS England. Next steps on the NHS five year forward view, 2017. Available: https://www.england.nhs.uk/wp-content/uploads/2017/03/ NEXT-STEPS-ON-THE-NHS-FIVE-YEAR-FORWARD-VIEW.pdf

10 Primary Care Foundation. Nhs alliance. making time in general practice, 2015. Available: http://www.primarycarefoundation.co.uk/ images/PrimaryCareFoundation/Downloading_Reports/PCF_Press Releases/Making-Time-in_General_Practice_FULL_REPORT_28_10_ 15.pdf

11 Mossialos E, Courtin E, Naci H, et al. From "retailers" to health care providers: Transforming the role of community pharmacists in chronic disease management. Health Policy 2015;119:628-39.

12 Pharmacy Voice. Community pharmacy forward view, 2016. Available: http://psnc.org.uk/wp-content/uploads/2016/08/CPFVAug-2016.pdf

13 Hall NJ, Donovan G, Wilkes S. A qualitative synthesis of pharmacist, other health professional and lay perspectives on the role of community pharmacy in facilitating care for people with long-term conditions. Res Social Adm Pharm 2018;14:1043-57.

14 Thornley T, Kirkdale C, Wright D. Demonstrating the patient benefit and value for the NHS of community pharmacy: insight from the community pharmacy future model. Clinical Pharmacist2017;9.

15 PSNC. Responding to the National review of asthma deaths (NRAD): the contribution that community pharmacies can make, 2014. Available: https://www.dispensingdoctor.org/wp-content/uploads/ 2015/02/PSNC-Response-to-NRAD-June-2014.pdf

16 Smith M. Pharmacists' role in improving diabetes medication management. J Diabetes Sci Technol 2009;3:175-9.

17 Hindi AMK, Jacobs S, Schafheutle El. Solidarity or dissonance? A systematic review of pharmacist and GP views on community pharmacy services in the UK. Health Soc Care Community 2019;27:565-98. 
18 Hindi AMK, Schafheutle El, Jacobs S. Patient and public perspectives of community pharmacies in the United Kingdom: a systematic review. Health Expect 2018;21:409-28.

19 Eades CE, Ferguson JS, O'Carroll RE. Public health in community pharmacy: a systematic review of pharmacist and consumer views. BMC Public Health 2011;11:582.

20 Hindi AMK, Schafheutle El, Jacobs S. Community pharmacy integration within the primary care pathway for people with longterm conditions: a focus group study of patients', pharmacists' and GPs' experiences and expectations. BMC Fam Pract 2019;20:26.

21 Worth A, Pinnock H, Fletcher M, et al. Systems for the management of respiratory disease in primary care--an international series: United Kingdom. Prim Care Respir J 2011;20:23-32.

22 PSNC. services database, 2019. Available: https://psnc.org.uk/ services-commissioning/services-database/

23 Jones SR, Carley S, Harrison M. An introduction to power and sample size estimation. Emergency Medicine Journal 2003;20:453-8.

24 Booms BH, Bitner M. Marketing of Services. In: Donnelly J, George WR, eds. Chicago, IL: American Marketing Association, 1981: 47-51.

25 Abedi G, Abedini E. Prioritizing of marketing mix elements effects on patients' tendency to the hospital using analytic hierarchy process. Int J Healthc Manag 2017;10:34-41.

$26 \mathrm{Su} \mathrm{L,} \mathrm{Li} \mathrm{T,} \mathrm{Hu} \mathrm{Y,} \mathrm{et} \mathrm{al.} \mathrm{Factor} \mathrm{analysis} \mathrm{on} \mathrm{marketing} \mathrm{mix} \mathrm{of} \mathrm{online}$ pharmacies - based on the online pharmacies in China. Journal of Medical Marketing 2013;13:93-101.

27 Franic DM, Haddock SM, Leslie Tootle T, et al. Pharmacy patronage: identifying key factors in the decision making process using the determinant attribute approach. Journal of the American Pharmacists Association 2008;48:71-86.

28 Ryan K, Gannon-Slater N, Culbertson MJ. Improving survey methods with cognitive interviews in small- and Medium-Scale evaluations. Am J Eval 2012;33:414-30.

29 Bursac Z, Gauss CH, Williams DK, et al. Purposeful selection of variables in logistic regression. Source Code Biol Med 2008;3:17.

30 MORI I. Gp patient Survey- technical Annex 2018 report 2018.

31 Bradley F, Ashcroft DM, Noyce PR. Integration and differentiation: a conceptual model of general practitioner and community pharmacist collaboration. Res Social Adm Pharm 2012;8:36-46.

32 Tinelli M, Bond C, Blenkinsopp A, et al. Patient evaluation of a community pharmacy medications management service. Ann Pharmacother 2007;41:1962-70.

33 Taylor J, Krska J, Mackridge A. A community pharmacy-based cardiovascular screening service: views of service users and the public. Int J Pharm Pract 2012;20:277-84.

34 Hindi A, Parkhurst C, Rashidi Y, et al. Development and utilization of the medicines use review patient satisfaction questionnaire. Patient Prefer Adherence 2017;11:1797-806.
35 Saramunee K, Dewsbury C, Cutler S, et al. Public attitudes towards community pharmacy attributes and preferences for methods for promotion of public health services. Public Health 2016;140:186-95.

36 Gammie S, Rodgers R, Loo RL, et al. Medicine-related services in community pharmacy: public preferences for pharmacy attributes and promotional methods and comparison with pharmacists' perceptions. Patient Prefer Adherence 2016;10:2297-307.

37 Saramunee K, Krska J, Mackridge A, et al. How to enhance public health service utilization in community pharmacy?: general public and health providers' perspectives. Res Social Adm Pharm 2014;10:272-84.

38 Gidman W, Ward P, McGregor L. Understanding public trust in services provided by community pharmacists relative to those provided by general practitioners: a qualitative study. BMJ Open 2012;2:e000939.

39 Hattingh HL, Emmerton L, Ng Cheong Tin P, et al. Utilization of community pharmacy space to enhance privacy: a qualitative study. Health Expect 2016;19:1098-110.

40 Gidman W, Cowley J. A qualitative exploration of opinions on the community pharmacists' role amongst the general public in Scotland. Int J Pharm Pract 2013;21:288-96.

41 Tully MP, Bozentko K, Clement S, et al. Investigating the extent to which patients should control access to patient records for research: a Deliberative process using citizens' juries. J Med Internet Res 2018;20:e112.

42 Feehan M, Walsh M, Godin J, et al. Patient preferences for healthcare delivery through community pharmacy settings in the USA: a discrete choice study. J Clin Pharm Ther 2017;42:738-49.

43 McMillan SS, Kelly F, Sav A, et al. Consumers and carers versus pharmacy staff: do their priorities for Australian pharmacy services align? Patient 2015;8:411-22.

44 Hann M, Schafheutle El, Bradley F, et al. Organisational and extraorganisational determinants of volume of service delivery by English community pharmacies: a cross-sectional survey and secondary data analysis. BMJ Open 2017;7:e017843.

45 Rapport F, Doel MA, Jerzembek GS. 'Convenient space' or 'a tight squeeze': insider views on the community pharmacy. Health Place 2009;15:315-22.

46 NHS. The NHS long term plan, 2019. Available: https://www. longtermplan.nhs.uk/wp-content/uploads/2019/01/nhs-long-termplan.pdf

47 Jacobs S, Fegan T, Bradley F, et al. How do organisational configuration and context influence the quantity and quality of NHS services provided by English community pharmacies? A qualitative investigation. PLoS One 2018;13:e0204304.

48 Bradley F, Wagner AC, Elvey R, et al. Determinants of the uptake of medicines use reviews (MURs) by community pharmacies in England: a multi-method study. Health Policy 2008;88:258-68. 